\title{
NGHIÊN CỨU ĐĂC ĐIỂM LÂM SÀNG HOANG TƯỞNG Ở BẾNH NHÂN LOẠN THẦN CẤP
}

\begin{abstract}
Đinh Việt Hùng ${ }^{1}$, Huỳnh Ngọc Lăng1, Phạm Ngọc Thảo ${ }^{1}$
TÓM TẮT.

Mục tiêu: nghiên cứu đặc điểm đặc điểm lâm sàng của hoang tưởng ở bênh nhân loạn thần cấp. Đối tượng và phương pháp nghiên cứu: 36 bệnh nhân điều trị tại Khoa Tâm thân, Bệnh viện Quân y 103 từ tháng 7/2018 đến tháng 7/2020. Kểt quả: Sự phân bố hoang tưởng của nhóm nghiên cứu là: hoang tưởng bị hại chiếm tới $73,53 \%$; có tới $86,11 \%$ có ảo giác và hoang tưởng kết hợp. Tân số ảo thanh hay gặp nhất là hàng ngày chiếm $82,14 \%$; Thái độ và hành vi của bệnh nhân loạn thần cấp đa số là tin tưởng và đáp ứng rõ với các hoang tưởng bị hại, hoang tưởng bị chi phối và hoang tương liên hệ với tý lệ từ 64,29\%-88\%. Đặc điểm rối loạn cảm xúc hay gặp nhất là trâm cảm chiếm 47,22\%; còn rối loạn hành vi hay gặp nhất là kích động chiếm $27,78 \%$. Sau 2 tuần điều trị thì hoang tưởng thuyên giảm hoàn toàn chiếm $91,18 \%$ và chỉ có $8,82 \%$ là thuyên giảm một phần. Kết luận: Hoang tướng là triệu chứng hay gặp và có vai trò quan trọng trong chẩn đoán loạn thần cấp với các đặc điểm đa dạng, phức tạp.

Tư khóa: Hoang tưởng, loạn thần cấp

\section{SUMMARY}

RESEARCH ON CLINICAL FEATURES OF DELUSIONS IN PATIENTS WITH ACUTE PSYCHOTIC DISORDER

Objective: To study clinical features of delusions in patients with acute psychotic disorder (APD). Objects and methods: 36 patients with APD were treated at Department of Psychiatry, Military Hospital

complex features.

Keywords: Delusions, acute psychotic disorder.

I. ĐẶT VẤN ĐỀ

Trên thế giới có hàng chục triệu người bị các bệnh lý tâm thần, chiếm khoảng $1-2 \%$ dân số thế giới và hàng năm tăng thêm $0,15 \%$ dân số. Tỷ lệ mắc bệnh này ở Việt Nam là $0,3-0,8 \%$ và hàng năm tắng thêm $0,1-0,15 \%$ dân số. Trong các bệnh lý tâm thần thì loạn thần cấp một nhóm bệnh loạn thần nặng, với đặc trưng là các triệu chứng loạn thần như hoang tưởng, ảo giác, căng trương lực, hành vi thanh xuân và ngôn ngữ thanh xuân. Các triệu chứng của loạn thần cấp rất đa dạng, phong phú và luôn thay đổi theo thời gian.

Trong loạn thần cấp thì triệu chứng hay gặp nhất là hoang tưởng với tỷ lệ $80-95 \%$ số bệnh nhân. Hoang tưởng bao gồm: hoang tưởng bị hại, hoang tưởng bị chi phối, hoang tưởng kỳ quái, hoang tưởng liên hệ, hoang tưởng tự cao và hoang tưởng nghi bênh. Bởi vậy, việc chẩn đoán chính xác và điều trị kịp thời loạn thần cấp là một vấn đề cần thiết trong thực hành lâm sàng. Vì vậy, chúng tôi tiến hành đề tài "Nghiên cứu đặc điểm lâm sàng hoang tưởng ở bệnh nhân loạn thần cấp".
\end{abstract} 103 from July 2018 to July 2020. Results: Distribution of delusions in research subjects including: Persecutory delusion accounted for $73.53 \%$, while $86.11 \%$ of patients suffered from both delusion and hallucination. Most of auditory hallucinations were experienced daily in $82.14 \%$ of patients; In terms of attitudes and behaviors, majority of patients with acute psychotic disorder believed in and massively responded to delusions of persecution, control, and reference with prevalence between $64.29 \%-88 \%$. The most common mood disorder was depressive disorder, accounting for $47.22 \%$; while the most common behavioral disorder was agitation, accounting for $27.78 \%$. After 2 week treatment, symptom of delusion being in full remission accounted for $91.18 \%$, whereas 8.82 of patients was in partial remission. Conclusion: Delusion is a common and relevant symptom in diagnosis of acute psychotic disorder with diverse and

1Bệnh viện Quân y 103

Chịu trách nhiệm chính: Đinh Việt Hùng

Email: bshunga6@gmail.com

Ngày nhận bài: 15.10 .2020

Ngày phản biện khoa học: 25.11.2020

Ngày duyệt bài: 4.12.2020

\section{II. ĐỐI TƯỢNG VÀ PHƯƠNG PHÁP NGHIÊN CỨU}

2.1. Đối tượng nghiên cứu. Đối tượng nghiên cứu gồm 36 bệnh nhân đáp ứng đầy đủ tiêu chuẩn chẩn đoán loạn thần cấp theo ICD-10 điều trị nội trú tại Khoa Tâm thần-Bệnh viện Quân y 103 từ tháng 7/2018 đến tháng 7/2020.

2.2. Phương pháp nghiên cứu. Sử dụng phương pháp nghiên cứu hồi cứu mô tả cắt ngang, phân tích đánh giá từng trường hợp cụ thể. Các triệu chứng lâm sàng được đánh giá trong ngày đầu bệnh nhân vào viện, việc đánh giá được tiến hành độc lập bởi hai bác sĩ chuyên nghành tâm thần.

2.3. Phân tích số liệu. Phân tích số liệu được tiến hành trên phần mềm phân tích số liệu SPSS 20.0. Sự khác biệt có ý nghĩa thống kê được xác định cho các kiểm định với mức $p<0,05$.

\section{KẾT QUẢ NGHIÊN CứU}

3.1. Đặc điểm chung của nhóm bệnh nhân nghiên cứu

Bảng 3.1. Đặc điểm về tuổi của nhóm 


nghiên cú́u
\begin{tabular}{|c|c|c|}
\hline Chỉ số thống kê & $\begin{array}{c}\text { Sô lươơng } \\
\text { (n) }\end{array}$ & $\begin{array}{c}\text { Tỷ lệ } \\
\mathbf{( \% )}\end{array}$ \\
\hline $\mathbf{2 h o ́ m}$ tuối & 6 & 16,67 \\
\hline $\mathbf{2 0 - 2 9}$ & 16 & 44,44 \\
\hline $\mathbf{3 0 - 3 9}$ & 8 & 22,22 \\
\hline $\mathbf{4 0 - 5 0}$ & 5 & 13,89 \\
\hline$>\mathbf{5 0}$ & 1 & 2,78 \\
\hline Tuối trung bình & \multicolumn{2}{|c|}{$28,25 \pm 11,37$} \\
\hline
\end{tabular}

Kết quả Bảng 3.1 chỉ ra rằng bệnh nhân loạn thần cấp đa số ở nhóm tuổi 20-29 chiếm 44,44\% và thấp nhất ở nhóm tuổi $>50$ chiếm $2,78 \%$ với tuổi trung bình là 28,25 11,37 .

Bảng 3.2. Đặc điểm về giới tính của nhóm nghiên cứu

\begin{tabular}{|c|c|c|}
\hline Giới tính & $\begin{array}{l}\text { Số lượng } \\
\text { (n) }\end{array}$ & $\begin{array}{l}\text { Tỷ lệ } \\
(\%)\end{array}$ \\
\hline Nam & 26 & 72,22 \\
\hline Nữ & 10 & 27,78 \\
\hline
\end{tabular}

Nghiên cứu của chúng tôi thu nhận được 26 bệnh nhân nam loạn thân cấp chiếm tỷ lệ $72,22 \%$ và 10 bệnh nhân nữ chiếm tỷ lệ $27,78 \%$.

Bảng 3.3. Nghề nghiệp của nhóm nghiên cứu

\begin{tabular}{|c|c|c|}
\hline Nghề nghiệp & $\begin{array}{c}\text { Cố lượng } \\
\text { (n) }\end{array}$ & $\begin{array}{c}\text { Tỷ lệ̂ } \\
\text { (\%) }\end{array}$ \\
\hline Bộ đội & 12 & 33,34 \\
\hline Cán bộ viên chức & 3 & 8,33 \\
\hline Công nhân & 5 & 13,89 \\
\hline Học sinh, sinh viên & 7 & 19,44 \\
\hline Nghề khác & 9 & 25,00 \\
\hline
\end{tabular}

Bảng 3.3 cho thấy bệnh nhân là bộ đội chiếm tỷ lệ cao nhất với 33,34\%, tiếp đến bệnh nhân làm nghề khác chiếm $25 \%$ và ít nhất bệnh nhân là cán bộ viên chức chiếm 8,33\%.

3.2. Các loại hoang tưởng thường gặp của nhóm nghiên cứu

Bảng 3.4. Các loại hoang tưởng của nhóm nghiên cứu

\begin{tabular}{|c|c|c|}
\hline Hoang tưởng & $\begin{array}{c}\text { Số lượng } \\
\text { (n) }\end{array}$ & $\begin{array}{c}\text { Tỷ leê } \\
\text { (\%) }\end{array}$ \\
\hline Hoang tưởng bị hại & 25 & 73,53 \\
\hline Hoang tưởng bị chi phối & 14 & 41,18 \\
\hline Hoang tưởng liên hế & 9 & 26,47 \\
\hline Hoang tưởng kỳ quái & 3 & 8,82 \\
\hline Hoang tưởng tự cao & 5 & 14,71 \\
\hline Hoang tưởng nghi bệnh & 4 & 11,76 \\
\hline
\end{tabular}

Trong 36 bệnh nhân loạn thần cấp thì có 34 bệnh nhân có hoang tưởng, trong đó: hoang tưởng bị hại chiếm tới 73,53\%; hoang tưởng bị chi phối $41,18 \%$; hoang tưởng liên hệ chiếm $26,47 \%$ và hoang tưởng kỳ quái thấp nhất chiếm 8,82\%.

Bảng 3.5. Sự kết hợp giữa ảo giác và hoang tưởng của nhóm nghiên cứu

\begin{tabular}{|c|c|c|}
\hline $\begin{array}{c}\text { Chỉ số thống kê } \\
\text { Đạ̣c điểm }\end{array}$ & $\begin{array}{c}\text { Số lượng } \\
\text { (n) }\end{array}$ & $\begin{array}{c}\text { Tỷ lệ } \\
\text { (\%) }\end{array}$ \\
\hline Áo giác đơn độc & 2 & 5,56 \\
\hline Áo giác và hoang tưởng & 31 & 86,11 \\
\hline Hoang tưởng đơn độc & 3 & 8,33 \\
\hline
\end{tabular}

Sự kết hợp giữa ảo giác và hoang tưởng của nhóm bệnh nhân nghiên cứu: 31 bệnh nhân $(86,11 \%)$ có ảo giác và hoang tưởng kết hợp; 3 bệnh nhân $(8,33 \%)$ là hoang tưởng đơn độc; 2 bệnh nhân $(5,56 \%)$ là ảo giác đơn độc.

3.3. Đặc điểm lâm sàng hoang tưởng của nhóm nghiên cứu

Bảng 3.6. Đặc điểm hành vi và thái độ hoang tưởng bị hại của nhóm nghiên cứu

\begin{tabular}{|c|c|c|c|}
\hline \multirow{2}{*}{ Đặc điểm } & Chí số thống kế & $\begin{array}{c}\text { Sô lượng } \\
(\mathbf{n})\end{array}$ & $\begin{array}{c}\text { Tỷ lề } \\
(\mathbf{\%})\end{array}$ \\
\hline \multirow{3}{*}{ Hành vi } & Đáp ứng rõ & 22 & 88,0 \\
\cline { 2 - 4 } & Đáp ứng tối thiểu & 3 & 12,0 \\
\cline { 2 - 4 } & Không đáp ứng & 0 & 0 \\
\hline \multirow{3}{*}{ Thái độ } & Tin tưởng & 19 & 76,0 \\
\cline { 2 - 4 } & Mơ hồ & 6 & 24,0 \\
\cline { 2 - 4 } & Không tin & 0 & 0 \\
\hline
\end{tabular}

Bảng 3.6 cho thấy hoang tưởng bị hại gặp ở 25 bênh nhân loạn thần cấp với thái độ đa số là tin tưởng chiếm $88 \%$; đồng thời hành vi của bệnh nhân loạn thần cấp là đáp ứng rõ với hoang tưởng bị hại chiếm 76\%.

Bảng 3.7. Đặc điểm hành vi và thái độ hoang tưởng bị chi phối của nhóm nghiên cứu

\begin{tabular}{|c|c|c|c|}
\hline \multirow{2}{*}{\multicolumn{2}{|c|}{ Đặc điểm Chỉ số thống kê }} & \multirow{3}{*}{$\begin{array}{c}\text { Sô lượng } \\
\text { (n) }\end{array}$} & \multirow{3}{*}{$\begin{array}{l}\begin{array}{l}\text { Tỷ lệ } \\
(\%)\end{array} \\
6429\end{array}$} \\
\hline & & & \\
\hline \multirow{3}{*}{ Thái đột } & Tin tưởng & & \\
\hline & Mơ hồ & 5 & 35,71 \\
\hline & Không tin & 0 & 0 \\
\hline \multirow{3}{*}{ Hành vi } & Đáp ứng rõ & 11 & 78,57 \\
\hline & Đáp ứng tối thiểu & 3 & 21,43 \\
\hline & Không đáp ứng & 0 & 0 \\
\hline
\end{tabular}

Bảng 3.7 cho thấy hoang tưởng bị chi phối gặp ở 14 bệnh nhân loạn thần cấp với thái độ đa số là tin tưởng chiếm 64,29\%; đồng thời hành vi của bệnh nhân loạn thần cấp là đáp ứng rõ với hoang tưởng bị chi phối chiếm 78,57\%.

Bảng 3.8. Đặc điểm hành vi và thái độ hoang tưởng liên hệ của nhóm nghiên cứu

\begin{tabular}{|c|c|c|c|}
\hline \multicolumn{2}{|c|}{ Đặc điểm Chỉ số thống kê } & $\begin{array}{c}\text { Sô lượng } \\
\text { (n) }\end{array}$ & $\begin{array}{l}\text { Tỷ lê̂ } \\
(\%)\end{array}$ \\
\hline \multirow{3}{*}{ Thái độ } & Tin tưởng & 7 & 77,78 \\
\hline & Mo hô & 2 & 22,22 \\
\hline & Không tin & 0 & 0 \\
\hline \multirow{3}{*}{ Hành vi } & Đáp ứng rõ & 6 & 66,67 \\
\hline & Đáp ứng tối thiếu & 3 & 33,33 \\
\hline & Không đáp ứng & 0 & 0 \\
\hline
\end{tabular}

Bảng 3.8 chỉ ra rằng hoang tưởng liên hệ gặp ở 9 bệnh nhân loạn thần cấp với thái độ đa số là 
tin tưởng chiếm $77,78 \%$; đồng thời hành vi của bệnh nhân loạn thần cấp là đáp ứng rõ với hoang tưởng liển hệ chiếm $66,67 \%$.

3.4. Đăc điểm rối loan cảm xúc và hành vi của nhóm nghiên cứu

Bảng 3.9. Đặc điểm về rối loạn cảm xúc của nhóm nghiên cúu

\begin{tabular}{|c|c|c|}
\hline Rối loạn cảm xức & $\begin{array}{c}\text { Số lượng } \\
\text { (n) }\end{array}$ & $\begin{array}{c}\text { Tỷ lệ̂ } \\
\text { (\%) }\end{array}$ \\
\hline Trầm cảm & 17 & 47,22 \\
\hline Hưng cảm & 10 & 27,78 \\
\hline Không thích hợp & 5 & 13,89 \\
\hline Hai chiều trái ngược & 4 & 11,11 \\
\hline
\end{tabular}

Kết quả Bảng 3.9 cho thấy đặc điểm rối loạn cảm xúc hay gặp nhất là trầm cảm chiểm $47,22 \%$; tiếp đó là hưng cảm chiếm $27,78 \%$ và thấp nhất là cảm xúc hai chiều trái ngược chiếm $11,11 \%$.

Bảng 3.10. Đặc điểm về rối loạn hành vi của nhóm nghiên cứu

\begin{tabular}{|c|c|c|}
\hline Rối loạn hành vìn & $\begin{array}{c}\text { Số lượng } \\
\text { (n) }\end{array}$ & $\begin{array}{c}\text { Tỷ lệ } \\
\text { (\%) }\end{array}$ \\
\hline Kích động & 10 & 27,78 \\
\hline Toan tự sát & 6 & 16,78 \\
\hline Hành vi dị thường & 5 & 13,89 \\
\hline
\end{tabular}

Bảng 3.10 cho thấy đặc điểm rối loạn hành vi hay gặp nhất là kích động chiếm $27,78 \%$; tiếp đó là toan tự sát chiếm $16,78 \%$ và thấp nhất là hành vi dị thường chiếm 13,89\%.

Bảng 3.11. Đặc điểm về triệu chứng loạn thần khác của nhóm nghiên cứu

\begin{tabular}{|c|c|c|}
\hline Đặc điểm Chỉ số thống kê & $\begin{array}{l}\text { Số lượng } \\
\text { (n) }\end{array}$ & $\begin{array}{l}\text { Tỷ lệ } \\
(\%)\end{array}$ \\
\hline Ngôn ngữ thanh xuân & 5 & 13,89 \\
\hline Hành vi thanh xuân & 4 & 11,11 \\
\hline Hành vi căng trương lực & 2 & 5,56 \\
\hline
\end{tabular}

Bảng 3.11 cho thấy đăcc điểm các triệu chứng loạn thần khác hay gặp ở bệnh nhân loạn thần cấp bao gồm ngôn ngữ thanh xuân chiếm 13,89\%; tiếp đó là hành vi thanh xuân chiếm $11,11 \%$ và thấp nhất là hành vi căng trương lực chiếm 5,56\%.

3.5. Kết quả điêu trị của nhóm nghiên cứu

Bảng 3.12. Kết quả điều trị hoang tưởng của nhóm nghiên cứu

\begin{tabular}{|c|c|c|}
\hline Đặc điểm Chỉ số thống kê & $\begin{array}{c}\text { Số lượng } \\
\text { (n) }\end{array}$ & $\begin{array}{c}\text { Tỷ lệ } \\
(\mathbf{\%})\end{array}$ \\
\hline Thuyên giảm hoàn toàn & 31 & 91,18 \\
\hline Thuyên giảm một phần & 3 & 8,82 \\
\hline
\end{tabular}

Sau 2 tuần điều trị thì hoang tưởng thuyên giảm hoàn toàn chiếm $91,18 \%$ và chỉ có $8,82 \%$ là thuyên giảm một phần.

\section{BÀN LUẬN}

\section{1. Đặc điểm chung của nhóm bệnh}

nhân nghiên cứu. Kết quả Bảng 3.1 chỉ ra rằng bệnh nhân loạn thần cấp đa số ở nhóm tuổi 2029 chiếm $44,44 \%$ và thấp nhất ở nhóm tuổi $>50$ chiếm 2,78\% với tuổi trung bình là 28,25 211,37 với tỷ lệ nam/nữ là $2,6 / 1$. Kết quả nghiên cứu của chúng tôi cho thây bệnh nhân là bộ đội chiếm tỷ lệ cao nhất với 33,34\%. Các kết quả này được giải thích bởi nghiên cứu của chúng tôi thực hiện tại Bệnh viện Quân y 103 là nơi điều trị cho các nam quan nhân mắc bệnh lý tâm thần chính vì vậy số lượng bệnh nhân nam sẽ cao hơn và phù hợp với nghiên cứu của tác giả trên thế giới về tuổi trung bình của loạn thần cấp [1].

4.2. Các loại ảo giác thường gặp của nhóm nghiên cứu. Sự phân bố hoang tưởng nhóm nghiên cứu là: hoang tưởng bị hại chiếm tới 73,53\%; hoang tưởng bị chi phối 41,18\%; hoang tưởng liên hệ chiếm $26,47 \%$ và hoang tưởng kỳ quái thấp nhất chiếm $8,82 \%$. Kết quả phù hợp với nghiên cứu López-Díaz Á. (2019) khi khẳng định sự phân bố của hoang tưởng không đồng đều trong đó hoang tưởng bị hại và hoang tưởng bị chi phối chiếm tỷ lệ cao lần lượt $64,32 \%$ và 35,41\% ở bệnh nhân loạn thần cấp [2].

Kết quả Bảng 3.5 cho thây ảo giác và hoang tưởng đơn độc ít gặp hơn lần lượt là $5,56 \%$ và $8,33 \%$, mà gặp chủ yếu là sự kết hợp giữa hoang tưởng và ảo giác chiếm $86,11 \%$; chính điều này hình thành các hành vi nguy hiểm của bệnh nhân loạn thần cấp [2].

4.3. Đặc điểm lâm sàng hoang tưởng của nhóm nghiên cứu. Bảng 3.6 cho thấy hoang tưởng bị hại gặp ở 73,53\% bệnh nhân loạn thần cấp với thái độ đa số là tin tưởng chiếm $88 \%$; đồng thời hành vi của bệnh nhân loạn thần cấp là đáp ứng rõ với hoang tưởng bị hại chiếm $76 \%$. Kết quả này phù hợp với nghiên cứu của Stentebjerg-Olesen M. (2016) khi thấy hoang tưởng bị hại chi phối hành vi và thái độ của bệnh nhân tới 67,34-82,31\% [3].

Đối với hoang tưởng bị chi phối gặp ở 14 bệnh nhân loạn thần cấp với thái độ đa số là tin tưởng chiếm $64,29 \%$; đồng thời hành vi của bệnh nhân loạn thần cấp là đáp ứng rõ với hoang tưởng bị chi phối chiếm 78,57\%. Đây chính là một trong những triệu chứng đặc trưng ở bệnh nhẩn loạn thần cấp và tâm thân phân liệt thể paranoid [4].

Đối với hoang tưởng liên hệ gặp ở 9 bệnh nhân loạn thần cấp với thái độ đa số là tin tưởng chiếm $77,78 \%$; đồng thời hành vi của bệnh nhân loạn thần cấp là đáp ứng rõ với hoang tưởng liên hệ chiếm $66,67 \%$. Kết quả nghiên cứu của chúng tôi phù hợp với nghiên cứu của Thom R.P. 
(2017) khi đưa ra kết luận rằng hoang tưởng liên hệ gặp ít hơn so với hoang tưởng bị hại, hoang tưởng bị chi phối nhưng lại là triệu chứng đặc trưng cho loạn thần cấp [5].

4.4. Đặc điểm rối loạn cảm xúc và hành vi của nhóm nghiên cứu. Kết quả Bảng 3.9 cho thấy đặc điểm rối loạn cảm xúc hay gặp nhất là trầm cảm chiếm 47,22\%; tiếp đó là hưng cảm chiếm $27,78 \%$ và thấp nhất là cảm xúc hai chiều trái ngược chiếm 11,11\%. Nghiên cứu của Foye U. (2019) đã chỉ ra rằng đây là các triệu chứng cốt lõi của loạn thần cấp và nhấn mạnh sự có mắt bắt buộc của các triệu chứng về cảm xúc ở bệnh nhân loạn thần cấp đó là trầm cảm và hưng cảm. Ngoài ra tác giả cũng nhấn mạnh các triêuu chứng khác về rối loạn cảm xúc như hai chiều trái ngược, cảm xúc không thích hợp [6].

Bảng 3.10 cho thấy đặc điểm rối loạn hành vi hay gặp nhất là kích động chiếm $27,78 \%$; tiếp đó là toan tự sát chiếm $16,78 \%$ và thấp nhất là hành vi bất động chiếm $5,56 \%$. Đây là các triệu chứng hay gặp bệnh nhân loạn thần cấp theo ICD 10-1992. Nghiên cứu về rối loạn hành vi ở bệnh nhân loạn thần cấp, Malhotra S. (2019) nhận thấy ngoài triệu chứng hay gặp là ý tưởng tự sát, kích động, nhiều bệnh nhân loạn thần cấp còn biểu hiện các rối loạn hành vi đa dạng khác: bất động, căng trương lực toàn thần, hành vi khác thường [7].

Bảng 3.11 cho thấy đặc điểm các triệu chứng loạn thần khác hay gặp ở bệnh nhân loạn thần cấp bao gồm ngôn ngữ thanh xuân chiếm $13,89 \%$; tiếp đó là hành vi thanh xuân chiếm $11,11 \%$ và thấp nhất là hành vi căng trương lực chiếm $5,56 \%$. Kết quả này phù hợp nhận định của Stentebjerg-Olesen M. (2016) khi thây ở bệnh nhân loạn thần cấp ngoài các triệu chứng hoang tưởng, ảo giác thì các triệu chứng như hành vi thanh xuân, ngôn ngữ thanh xuân và hành vi căng trương lực cũng hay gặp dù chiếm tỷ lệ không cao [3].

4.5. Kết quả điêuu trị của ảo giác ở nhóm nghiên cứu. Cùng với sự xuất hiện của các loại thuốc an thần mới như clozapine, risperidol, olanzapine và seroquel, đồng thời các kỹ thuật chuyên sâu trong chăm sóc sức khỏe tâm thần được áp dụng như sốc điện cổ điển, sốc điện gây mê. Nên hiệu quả điều trị được nâng cao, sau 2 tuần điều trị thì hoang tưởng thuyên giảm hoàn toàn chiếm $91,18 \%$ và chỉ có $8,82 \%$ là thuyên giảm một phần. Kết quả nghiên cứu của chúng tôi phù hợp với nghiên cứu của Maley C.T. (2019) các thuốc an thần mới và sốc điện đã phát huy tác dụng trên bệnh nhân loạn thần cấp, mặc dù liều lượng thấp và thời gian điều trị ngắn. Có một số nhỏ bệnh nhân thuyên giảm chậm bởi vì bệnh nhân loạn thần cấp mức độ nặng, nên hoang tưởng tồn tại lâu hơn [8].

\section{KẾT LUẬN}

Sự phân bố hoang tưởng của nhóm nghiên cứu là: hoang tưởng bị hại chiếm tới $73,53 \%$; hoang tưởng bị chi phối 41,18\%; hoang tưởng liên hệ chiếm $26,47 \%$ và hoang tưởng kỳ quái thấp nhất chiếm 8,82\%. Có 31 bệnh nhân $(86,11 \%)$ có ảo giác và hoang tưởng kểt hợp.

Thái độ và hành vi của bệnh nhân loạn thần cấp đa số là tin tưởng và đáp ứng rõ với các hoang tưởng bị hại, hoang tưởng bị chi phối và hoang tương liên hệ với tỷ lệ từ 64,29\%-88\%.

Đặc điểm rối loạn cảm xúc hay gặp nhất là trầm cảm chiếm 47,22\%; còn rối loạn hành vi hay gặp nhất là kích động chiếm $27,78 \%$. Sau 2 tuần điêu trị thì hoang tưởng thuyên giảm hoàn toàn chiếm $91,18 \%$ và chỉ có $8,82 \%$ là thuyên giảm một phần.

\section{TÀI LIẸU THAM KHẢO}

1. Bùi Quang Huy, Phùng Thanh Hải, Đinh Việt Hùng (2016), Tâm thần phân liệt nguyên nhân, chẩn đoán và điều trị, Nhà xuất bản Y học, Hà Nội.

2. López-Díaz Á., Fernández-González J.L., Lara I., et al. (2019), "The prognostic role of catatonia, hallucinations, and symptoms of schizophrenia in acute and transient psychosis". Acta Psychiatr Scand; 140(6): 574-585.

3. Stentebjerg-Olesen M., Pagsberg A.K., FinkJensen A., et al. (2016), "Clinical characteristics and predictors of outcome of schizophrenia-spectrum psychosis in children and adolescents: A systematic review". J Child Adolesc Psychopharmacol; 26(5): 410-427.

4. Correll C.U., Brevig T. and Brain C. (2019), "Patient characteristics, burden and pharmacotherapy of treatmentresistant schizophrenia: results from a survey of 204 US psychiatrists". BMC Psychiatry; 19(1): 362.

5. Thom R.P. and Fromson J.A. (2017), "Olfactory hallucinations as the presenting
symptom in acute psychosis". Prim Care Companion CNS Disord; 19 (5): 17102098.

6. Foye U., Hazlett D.E. and Irving P. (2019), "Exploring the role of emotional intelligence on disorder eating psychopathology". Eat Weight Disord; 24(2): 299-306.

7. Malhotra S., Sahoo $\mathbf{S}$ and Balachander S. (2019), "Acute and transient psychotic disorders: Newer understanding". Curr Psychiatry Rep; 21(11): 113

8. Maley C.T., Becker J.E. and Shultz E.K.B. (2019), "Electroconvulsive therapy and other neuromodulation techniques for the treatment of psychosis". Child Adolesc Psychiatr Clin N Am; 28(1): 91-100. 